\title{
A QUESTÃO AGRÁRIA EM MATO GROSSO DO SUL
}

\author{
Recebido em 20/01/2020, aprovado em 13/03/2020 \\ 10.30612/mvt.v6i11.10919 \\ André Alexandre Ricco de Freitas ${ }^{1}$
}

\begin{abstract}
RESUMO: A questão agrária em Mato Grosso do Sul está ligada à relação conflituosa entre concentração fundiária e a luta pela terra. Para compreender como se dá esta relação faremos uma breve explanação sobre os conflitos agrários que marcaram o início da implantação da reforma agrária no estado e que culminou com o surgimento dos movimentos sociais de luta pela terra. Trataremos ainda sobre os entraves na política agrária causada pela modernização da produção agropecuária que se intensificou com o processo de agroindustrialização culminando com a expansão do agronegócio que por sua vez vem afetando a política de criação de assentamentos rurais. Debateremos ainda, como a consolidação do agronegócio se tornou um entrave para a política agrária e como apesar das dificuldades foi possível a criação de um número significativo de assentamentos rurais no estado onde vive e trabalham grande parte da população rural sul-mato-grossense.
\end{abstract}

Palavras-chave: Reforma Agrária. Movimentos Sociais. Assentamentos.

\section{THE AGRARIAN QUESTION IN MATO GROSSO DO SUL}

ABSTRACT: The agrarian issue in Mato Grosso do Sul is linked to the conflicting relationship between land concentration and the struggle for land. In order to understand how this relationship takes place, we will briefly explain the agrarian conflicts that marked the beginning of the implementation of agrarian reform in the state and which culminated in the emergence of social movements fighting for land. We will also deal with the obstacles in the agrarian policy caused by the modernization of agricultural production that intensified with the agroindustrialization process culminating in the expansion of agribusiness, which in turn has been affecting the policy of creating rural settlements. We will also discuss how the consolidation of agribusiness has become an obstacle to agrarian policy and how despite the difficulties it was possible to create a significant number of rural settlements in the state where a large part of the rural population of Mato Grosso do Sul lives and works.

Keywords: Agrarian Reform. Social Movements. Settlements.

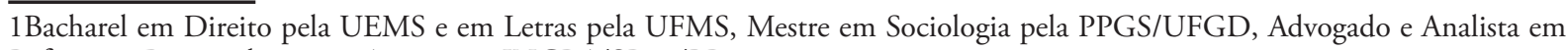
Reforma e Desenvolvimento Agrário no INCRA/SR18/PB. 


\section{LA CUESTIÓN AGRARIA EN MATO GROSSO DO SUL}

RESUMEN: La cuestión agraria en Mato Grosso do Sul está vinculada a la relación conflictiva entre la concentración de la tierra y la lucha por la tierra. Para comprender cómo se produce esta relación, explicaremos brevemente los conflictos agrarios que marcaron el inicio de la implementación de la reforma agraria en el Estado y que culminaron con el surgimiento de los movimientos sociales de lucha por la tierra. También abordaremos los obstáculos en la política agraria causados por la modernización de la producción agrícola que se ha intensificado con el proceso de agroindustrialización, culminando con la expansión de la agroindustria, que a su vez ha afectado la política de creación de asentamientos rurales. También discutiremos cómo la consolidación del agronegocio se ha convertido en un obstáculo para la política agraria y cómo, a pesar de las dificultades, ha sido posible crear un número significativo de asentamientos rurales en el estado donde vive y trabaja una gran parte de la población rural de Mato Grosso do Sul.

Palavras claves: Reforma Agraria. Movimientos Sociales. Asentamientos.

\section{INTRODUÇÃO}

A questão agrária em Mato Grosso do Sul está ligada a relação conflituosa entre à concentração fundiária e a luta pela terra sobre as quais iremos discorrer ao longo deste artigo. Para compreender como se dá esta relação faremos uma breve explanação sobre os conflitos agrários que marcaram o início da reforma agrária no estado e que culminou com o surgimento dos movimentos sociais de luta pela terra.

Trataremos também sobre os entraves na política agrária causada pela modernização da produção agropecuária e que se intensificou com o processo de industrialização da agricultura afetando a política de criação de assentamentos rurais no estado. Debateremos ainda como a consolidação do agronegócio se tornou um entrave para a política agrária e como apesar das dificuldades foi possível a criação de um número significativo de assentamentos rurais onde vive e trabalha grande parte da população rural sul-mato-grossense.

\section{A CONCENTRAÇÃO FUNDIÁRIA}

O Estado de Mato Grosso do Sul possui uma área total é de $357.145,53$ km² e uma população estimada em 2.748.023 habitantes, de modo, que possui uma baixa densidade demográfica de apenas 6,86 habitantes por quilometro quadrado (IBGE, 2010). Apesar da grande extensão do seu território o estado possui somente setenta e nove municípios que se destacam sobretudo pela produção agrícola em grandes propriedades rurais constituindo o quinto estado brasileiro com a maior concentração de terras do país (NERA, 2016).

Nossa hipótese é que esta alta concentração fundiária está relacionada ao processo de ocupação e formação do seu território que teria promovido a exclusão de milhares de famílias de trabalhadores rurais do campo e o aumento dos conflitos agrários culminando com a consolidação de uma economia rural excludente baseada no modelo de produção agroindustrial. 
O nível de desigualdade na distribuição das terras no estado também pode ser verificado pela composição da sua estrutura fundiária indicando que embora apenas 13\% dos imóveis rurais do estado sejam consideradas grandes propriedades rurais detém mais de $70 \%$ de sua área, enquanto os minifúndios que correspondem a $46 \%$ dos imóveis rurais detêm apenas $2,12 \%$ da área total do estado (INCRA, 2019).

Este alto grau de concentração fundiária demonstra ainda que a política agrária não foi insuficiente para superar os desafios decorrentes da expansáo do desenvolvimento capitalista no meio rural servindo apenas para diminuir os impactos socioeconômicos causados pela modernização da agricultura, sem, contudo, promover uma alteração na estrutura fundiária.

Acredita-se ainda que a concentração de terras se deve a dinâmica da própria história econômica do Brasil, que segundo Prado Junior (1979) seria o resultado de sua formação agrária, com acentuado grau de concentraçáo da propriedade fundiária. Portanto, "é reflexo da natureza de nossa economia, tal como resulta da formação do país desde os primórdios da colonização, e como se perpetua, em suas linhas gerais e fundamentais, até os nossos dias” (PRADO, 1979, p. 47).

Assim a realidade fundiária de Mato Grosso do Sul não difere muito da situação agrária do restante do país, caracterizada pela concentraçáo de terras e pela exploração da agricultura em grandes propriedades rurais, por este motivo se faz necessário ampliar o debate em torno da questão agrária no estado com suas especificidades históricas que desencadearam a luta pela terra e a implantaçáo de assentamentos rurais.

\section{OS PRINCIPAIS CONFLITOS AGRÁRIOS}

Para conter a expansão do setor agropecuário que avançava sobre as pequenas propriedades rurais expulsando a população do campo foi necessário que os trabalhadores rurais se organizassem para resistir a expansão do latifúndio e, mais tarde, contra a monopolização dos recursos naturais pelas grandes empresas agroindustriais. $\mathrm{O}$ êxito da luta pela terra dependia então da organização desses sujeitos sociais para exercerem pressão sobre o governo visando o atendimento de suas reivindicaçôes manifestadas principalmente pelas ocupaçóes de terras e acampamentos ao longo das rodovias.

Um dos primeiros conflitos agrários que contou com uma organização efetiva dos trabalhadores rurais no estado ocorreu em 1979, com o conflito entre arrendatários e proprietários das fazendas Entre Rios, Água Doce e Jequitibá no município de Naviraí. Segundo Cortez (1985):

\footnotetext{
Neste ano 250 famílias de arrendatários entram na Justiça contra os proprietários das fazendas, através do advogado Joaquim das Neves Nortes, denunciando as constantes ameaças de agressóes e despejo por parte dos fazendeiros e reivindicando a permanência na área por mais três anos, conforme o estatuto da terra (CORTEZ; , 1985, p. 3).
}

Este conflito que perdurou até meados de 1980 culminando com o ganho de causa pelos arrendatários e no assassinato do advogado Joaquim das Neves Nortes que representava judicialmente os arrendatários, causando grande comoção social. Após este episódio o governo estadual lançou um 
projeto que visava dar assistência ao pequeno produtor, comprovando a eficácia das ocupaçóes no atendimento das demandas sociais.

Outro conflito agrário emblemático ocorrido durante este período e que demonstra a importância da organização dos trabalhadores rurais na luta pela terra foram as tentativas de ocupaçáo da Fazenda Santa Idalina no município de Ivinhema por mais de mil famílias de trabalhadores rurais expulsos do campo pela modernização da agricultura. Esta fazenda constituía em uma gleba rural com mais de 18 mil hectares totalmente ociosos, pertencentes a Sociedade de Melhoramentos Ltda. - SOMECO, uma empresa imobiliária do interior do estado de São Paulo que adquiriu terras no estado para fins especulativos.

Embora malsucedida na primeira tentativa, a ocupação da Fazenda Santa Idalina constituiu um dos eventos de maior importância para reforma agrária em Mato Grosso do Sul pois marcou o início da luta pela terra no estado (VANESKI FILHO, 2016 p. 134). Este início de luta contou com a participação da Comissão Pastoral da Terra - CPT que atuou diretamente na organização dos trabalhadores rurais colaborando para a formação dos primeiros movimentos sociais do estado. Para Melo (2017):

O fato é que a ocupação da Idalina constituiu-se num marco histórico da mobilização dos Trabalhadores Rurais Sem Terra na luta pela terra. Desencadeiamse a partir daí, nos anos seguintes, [...] ocupaçóes e acampamentos com maior ou menor organização dos mesmos (CPT, 1994 apud MELO, 2017, p. 143).

Apesar desses trabalhadores rurais terem sido despejados pela justiça e encaminhados para outros acampamentos improvisado, essa propriedade foi ocupada novamente pelo outros movimentos sociais e acabou sendo desapropriada e transformada no que viria a ser um dos primeiros assentamentos rurais dos estado, sendo chamado de Projeto de Assentamento Novo Horizonte, criado em 10 de abril de 1986 para abrigar diversas famílias de trabalhadores rurais brasileiros expulsos do Paraguai os chamados "brasiguaios", vindo a dar origem ao município de Novo Horizonte do Sul. Segundo Freitas (2018):

O retorno dos "brasiguaios" coincidiu com as primeiras açôes visando a implantação da RA em MS, objetivando atender esta demanda que extrapolava os limites territoriais do estado brasileiro, o governo federal procurou dar prioridade no atendimento desses imigrantes, ao mesmo tempo em que buscou impedir o deslocamento para a regiāo, de mais contingentes vindo do Paraguai (FREITAS, 2018, p. 362).

Esses dois casos emblemáticos demonstram que êxito na implantação da reforma agrária se deve a organização dos trabalhadores em torno da luta pela terra, pois quanto maior a pressão sobre o governo maior será a prioridade para seu atendimento pelos órgãos estatais, de modo, que é impossível não relacionar a criação de assentamentos com as ocupaçóes e acampamentos promovidos pelos movimentos sociais criados pelos trabalhadores rurais. 


\section{OS MOVIMENTOS SOCIAIS DE LUTA PELA TERRA}

As conquistas em torno da luta pela terra em Mato Grosso do Sul estão relacionadas a capacidade de organização trabalhadores rurais em torno de suas pautas sociais que são reivindicadas sobretudo por meio de ocupaçóes de terras e acampamentos promovidos pelos movimentos sociais. Assim, conhecer um pouco sobre esta forma organizaçáo popular é importante para entender a dinâmica em torno questáo agrária uma vez que os eventos por eles promovidos ajudam a compreender como se deu o processo de implantação da reforma agrária no estado.

Os movimentos sociais de luta pela terra que surgiram no estado a partir da década de 1980 são organizaçôes de trabalhadores rurais criados para combater as contradiçôes do modo de produção capitalista que vigora até hoje em nossa sociedade, visto que desde o início de sua criaçáo os movimentos sociais já denunciavam e chamavam a atenção para os limites do modelo socioeconômico e político e, apontavam para novas formas de organização do trabalho e produção que surgiram (COELHO, 2010, p. 44).

Em Mato Grosso do Sul os movimentos sociais de luta pela terra se constituíram a partir de duas frentes populares, sendo que a primeira ligada aos Sindicatos dos Trabalhadores Rurais - STR que em sua síntese são legatários das Ligas Camponesas, extintas na década de 1960 pela perseguição do regime militar. Neste sentido Almeida (2003) afirma que:

Os movimentos sociais populares foram gestados a partir da década de 1970 , e
trazem uma nova compreensão da sociedade. Esses movimentos sociais diferem-
se dos antecessores (1945-1960), por apregoarem uma concepçáo de sociedade
pautada na diminuição doautoritarismo, das estruturas hierárquicas ecentralizadas.
Destarte, as lutas populares vivenciadas no cotidiano que se desenvolveram pós-
1964 inauguraram uma nova concepção de política, experimentando formas
organizativas de auto-gestão, autoavaliação e centros decisórios múltiplos, sob
uma organização mais ou menos definida (direção não espontânea) (ALMEIDA,
2003, p. 178).

A segunda frente popular estava ligada à Igreja Católica através da Comissão Pastoral da Terra - CPT que teve grande importância na luta pela terra no estado durante as décadas de 1970 e 1980, tendo como objetivo principal a luta contra a exploraçáo do trabalho, expropriaçóes, democratização ao acesso à terra e concentração fundiária. Segundo Borges e Kudlavicz (2008):

[...] a criação da CPT no MS ocorreu na década de 1970, num cenário político e social muito difícil, marcado pela violência e repressão. A CPT surge em 1978, com o intuito de contribuir no meio rural, sendo um espaço de reflexão para os camponeses poderem se articular. Participando ativamente das açóes do campesinato organizado, na forma de ocupaçôes e manifestaçóes, bem como despejos e ajudas nas negociaçóes (BORGES; KUDLAVICZ, 2008, p. 15).

A CPT surgiu em plena ditadura militar em Goiânia no estado de Goiás por volta de 1975, tendo como base a teologia da libertaçáo. Segundo Coelho (2010) ela teve grande peso em meio à luta pela terra, pois mesmo sendo dirigida por uma minoria de agentes religiosos progressistas podia falar em nome da Instituiçáo e dispor de seus recursos materiais e humanos. Para o autor ela: 
[...] nasceu sob contradiçóes tanto da sociedade como um todo, com o poder exercido sobre ela; quanto das contradiçóes geradas internamente nas Instituiçóes eclesiásticas que participavam desta Comissão. Nota-se que em meio às práticas da CPT houve um enfrentamento da Igreja com as classes dominantes, à medida que suas visōes estariam direcionadas às aspiraçóes das classes oprimidas no campo (COELHO, 2010, p. 73).

Vale ressaltar que entre 1987 e 1988, a CPT deixou de atuar na chamada "frente de massa" para auxiliar na permanência do trabalhador rural na terra. Dessa forma, a partir da década de 1990 ela passou a dirigir sua prática preferencialmente para os assentamentos, ou seja, ela passa a apoiar os trabalhadores rurais já assentados em projetos oficiais de reforma agrária, priorizando assim a luta na terra, e não a luta pela terra (SILVA, 2004, p. 44).

Atualmente existem diversas organizaçóes sociais no estado que visam promover a pauta da reforma agrária e a luta pela distribuição de terras que geralmente estão distribuídos nacionalmente através de suas regionais que organizam milhares de famílias de trabalhadores rurais, sendo que no estado destacamos o MST, a FETAGRI, a CUT, a FAF, entre outros.

Existem ainda outras organizaçóes sociais que foram criadas a partir de divergências ou desmembramento desses movimentos sociais, e outras que embora estejam ligadas a atuação sindical ou religiosas serão consideradas como movimentos sociais para fins deste estudo, pois compartilham com estes as mesmas formas de organização e a pauta de luta pela terra.

Além disso existem ainda várias associaçóes e entidades que embora tenham a mesma pauta não compartilham da mesma forma de organização, porém atuam diretamente na luta pela reforma agrária e pelo fortalecimento da agricultura familiar e que, por isso, também podem considerados como movimentos sociais como por exemplo, a Central dos Trabalhadores do Brasil - CTB, Organização de Luta pela Terra - OLT, Movimento das Mulheres Camponesas - MMC, o Movimento Camponês de Luta pela Reforma Agrária -MCLRA, entre outros.

Embora a luta pela terra no estado não se restrinja as organizaçôes acima descritas, estas constituem os principais movimentos sociais em atividades no estado, porém a esses se somam diversas outras organizaçôes de luta camponesa, incluindo os movimentos da populaçáo indígena que embora não tenham uma organização similar nem a mesma pauta pela reforma agrária com os movimentos sociais são responsáveis para maioria dos acampamentos e ocupaçóes de terras no estado atualmente.

Desse modo, a principal contribuição dos movimentos sociais por uma melhor distribuição de terras, considerando todas as organizaçóes de luta pela terra, está ligada à organização das manifestaçóes populares principalmente através de ocupaçôes e acampamentos rurais.

Um dos primeiros episódios em que os movimentos sociais tiveram grande importância na luta pela reforma agrária no estado foi na organização do acampamento de "brasiguaios" em Mundo Novo em 1984. Essa mobilização contou com o apoio da Comissão Pastoral da Terra - CPT e da Comissão Estadual de Sem-terra até 1985, quando esta comissão tornou-se efetivamente o Movimentos dos trabalhadores Rurais Sem Terra - MST, e passou assumir o acompanhamento da luta dos brasiguaios (FALCHI, 2007, p. 52).

Neste mesmo período houve várias situaçôes de acampamentos e ocupaçôes com a participação direta dos movimentos sociais, entre eles a própria CPT, o MST e a FETAGRI, entre outros. Além do acampamento de Mundo Novo havia outros acampamentos de brasiguaios em Sete Quedas e Eldorado. Em Naviraí, encontravam-se acampados grande parte dos arrendatários expulsos das fazendas Entre-Rios, Água Doce e Jequitibá. Além disso, as famílias que foram despejadas da ocupação 
da Gleba Santa Idalina em Ivinhema, acabaram acampando na Vila São Pedro em Dourados, de onde foram encaminhados para o local onde seria instalado o Projeto de Assentamento Padroeira do Brasil em Nioaque.

Segundo Menegat (2009), no ano de 1985, havia ainda, diversos acampamentos nas cidades da regiáo da grande Dourados, como Jateí, Fátima do Sul, Glória de Dourados entre outras, sendo que ao final daquele ano todos os acampamentos dessa regiáo foram reunidos em um único local, próximo ao terminal rodoviário de Dourados, onde as famílias permaneceram por aproximadamente um ano (MENEGAT, 2009, p. 72).

Posteriormente grande parte dos acampamentos que existiam em Mato Grosso do Sul foram centralizados em um grande acampamento chamado Santo Inácio em Dois Irmãos do Buriti, criado pelo governo estadual para reunir os acampamentos de sem-terra, que haviam se instalado em diversas cidades do estado para depois serem distribuídos em assentamentos criados pelo INCRA (MENEGAT, 2009, p. 56).

Como se pode verificar a organização dos trabalhadores rurais através dos movimentos sociais tiveram especial importância na luta pela terra no estado especialmente para a implantaçáo da reforma agrária, isto porque a distribuição de terras a partir da criação de assentamentos rurais não foi fruto de uma política agrária planejada e organizada, mas resultado da pressão política exercida sobre o governo através das ocupaçóes e acampamentos exigindo a criação de assentamentos rurais.

\section{O AGRONEGÓCIO E A POLITIICA AGRÁRIA}

A política agrária em Mato Grosso do Sul tem passado por diversas situaçóes que a impedem de servir como um instrumento eficaz de democratizaçáo do acesso à terra e de diminuiçáo da pobreza no campo. Esses entraves decorrem não somente das dificuldades técnicas e políticas, mas sobretudo econômica causada pela industrialização da atividade agropecuária que vem monopolizando os recursos públicos disponíveis para a produção agrícola, além de promover a concentração fundiária, a diminuiçáo da oferta de terras e o encarecimento do preço das propriedades rurais passíveis de aquisição para reforma agrária.

Desde a emancipação política de Mato Grosso do Sul em 1977, o estado manteve sua economia voltada para a exploração agrícola e pecuária em grande escala visando o atendimento da indústria nacional e do mercado internacional de commodities agrícolas. Assim, a produção agropecuária em grandes propriedades rurais sempre deteve uma parcela significativa da capacidade produtiva do estado, graças a monopolização dos financiamentos da agricultura e incentivos fiscais disponibilizados pela política agrícola nacional a partir da década de 1980 .

Com a intensificação da mecanização e da tecnificação da produção agrícola ocorrida nos anos de 1990, a atividade agropecuária passou por um processo de industrializaçáo atraindo empresas multinacionais do setor alimentício (voltada principalmente para a produção de carnes e da cultura do milho e da soja) e extrativista (com a produção de eucalipto e cana-de-açúcar) e alterando o perfil econômico do estado que passou a ser industrializar. Neste sentido, Buscioli e Souza (2010) afirmam que:

A motivação industrializante registrada em Mato Grosso do Sul a partir da segunda metade dos anos de 1980 estava pautada na agroindústria e constituíase em concordância ao comportamento da indústria nacional e da demanda 
internacional, além de significar a mudança do perfil agrário- exportador de Mato Grosso do Sul (BUSCIOLI; SOUZA, 2010, p. 133).

Este processo de industrialização da produção agropecuária e extrativista, juntamente com a chegada de empresas multinacionais do setor agrícola e sua integraçáo econômica ao mercado internacional de commodities, culminou na consolidação de toda a cadeia produtiva agroindustrial, o que a partir do ano 2000 passou a ser conhecida como "agronegócio".

A consolidação deste processo de agroindustrialização a partir da década de 2000, foi responsável crescimento econômico de Mato Grosso do Sul, tendo um papel relevante na balança comercial do estado relacionado diretamente ao implemento do setor primário e, portanto, como participaçáo na cadeia de produção agrícola incentivada pelo aumento das trocas comerciais.

Entretanto, o "mito" de que Mato Grosso do Sul é um estado eminentemente agrícola e exportador como o foi nos séculos passados vem se alterando ao longo das últimas décadas passando a se tornar um estado cada vez mais industrializado. Atualmente o setor de serviços detém quase cinquenta e cinco por cento da atividade econômica do estado, enquanto a indústria detém vinte por cento, ficando o setor agropecuário com apenas quinze por cento de participação na economia, segundo os dados divulgados pela Secretaria Estadual de Meio Ambiente e Desenvolvimento (SEMADE, 2018, p. 51).

Assim o privilégio que os órgãos governamentais têm dedicado ao setor agropecuário em detrimento dos demais setores da economia - náo se justifica mais, devido a sua menor participaçáo na composição econômica do estado. Portanto, a hegemonia do setor agropecuário no partilhamento dos recursos públicos especialmente através da monopolização dos créditos agrícolas e subsídios fiscais e que vem prejudicando a política agrária só pode ser atribuída à influência política exercida pela elite ruralista do estado.

Neste sentido, o crescimento econômico do estado decorrente da consolidação do agronegócio tem afetado diretamente a política agrária, na medida em que mantém a concentração fundiária, promovendo a exclusão dos trabalhadores rurais dos territórios tradicionalmente ocupados, resultando no desemprego, na pobreza e na miséria no meio rural sul-mato-grossense (FABRINI, 2008, p. 78).

Isto se deve ao fato de que as principais culturas agrícolas produzidạs em Mato Grosso do Sul (tradicionalmente a soja, o milho e a pecuária) demandam a utilização de grandes áreas de terras fazendo com que a agriculta monopolize os recursos naturais e restringindo o acesso dos pequenos produtores e trabalhadores rurais ao resultado econômico da agricultura.

Além disso, atualmente vem ocorrendo um crescimento exponencial da área de plantio devido ao arrendamento de grandes extensóes de terras necessárias para as plantaçóes da cana de açúcar que estão distribuídas praticamente em todo o estado voltada principalmente para a produção de etanol, e também do eucalipto para atendimento das grandes usinas de beneficiamento de papel e celulose que se estabeleceram na regiáo leste do estado.

Essas atividades além de promoverem ainda mais a concentração fundiária no estado, vem causando grande impacto ambiental devido ao uso intensivo dos solos e dos recursos hídricos e, sobretudo, pelo uso indiscriminado de fertilizantes, defensivos agrícolas e insumos químicos que acabam esgotando os recursos naturais existentes, por isso, depois de certo tempo esses locais acabam sendo abandonados e oferecidos para ao governo para a criação de assentamentos rurais.

Assim a reforma agrária acaba sendo feita em áreas reformadas ou que não servem mais para o agronegócio e que acabam sendo desapropriadas ou compradas pelo governo visando criaçáo de 
assentamentos rurais. Porém as propriedades adquiridas muitas vezes náo permitem o desenvolvimento da agricultura familiar sem a utilização de grandes investimentos materiais e financeiros para recuperação ambiental causando ainda mais dificuldades para as famílias assentadas.

Além de estimular o domínio do capital sobre o trabalho e a produção, o agronegócio vem aquecendo o mercado de terras por meio da comercialização e, sobretudo, pelo arrendamento de grandes extensôes rurais tornando cada vez mais onerosa a obtenção de terras para criação de novos assentamentos rurais. Tal fato constitui o que Oliveira (2012), tem chamado de "deserto verde", que tem aumentado o preço das propriedades rurais no estado e diminuindo o estoque de terras disponíveis para reforma agrária, especialmente na região oeste do estado, segundo o autor:

Tem-se assim na microrregiâo de Três Lagoas, por conta do eucalipto, e no território sul mato-grossense em virtude da soja e mais recentemente da cana-deaçúcar, a constituição de um grande "deserto verde" apoiado na estrutura fundiária concentracionista e na aliança latifundiários-capitalistas, solapando qualquer perspectiva de reforma agrária pela via da desapropriaçáo de terras improdutivas (OLIVEIRA, 2012, p. 11).

Outro entrave que tem dificultado a implantação de política agrária em Mato Grosso do Sul é a possibilidade de aquisiçáo de terras por estrangeiros, assunto este de especial interesse não somente porque o estado possui mais de 1.500 quilômetros de fronteira seca com dois países (Paraguai e Bolívia), mas porque está diretamente relacionado à produçáo agroindustrial por uma infinidade de empresas multinacionais que aqui se instalaram nos últimos anos, como a Bunge Alimentos S.A, Cargill Agrícola S.A, ADM do Brasil Ltda., Adecoagro Brasil Participaçóes S.A etc.

Essas empresas multinacionais atuam em Mato Grosso do Sul não somente na produção agrícola em áreas arrendadas, já que a legislação brasileira limita a aquisição de terras por empresas estrangeiras, mas no próprio mercado de terras através da intermediaçáo de vendas e arrendamentos de propriedades rurais. Assim, apesar de impedir maiores investimentos internacionais na agricultura, esta limitação legal constitui uma importante ferramenta para evitar a perda da soberania nacional sobre as áreas ocupadas pelo agronegócio, assegurando a manutenção da segurança nacional e a prevenção contra especulação imobiliária.

Entretanto para a política agrária, a atenção especial com relação a aquisição de terras por estrangeiros se deve pelos mesmos motivos causados pelo agronegócio, do qual está diretamente relacionado, que é o impacto no preço das terras e na diminuição da disponibilidade de propriedades passíveis de aquisição para fins de reforma agrária, pois a entrada de estrangeiros tem influenciado os preços de terra no cenário nacional, já que estes agentes atuam como fortes demandantes, influenciando a precificação das terras nacionais (CASTILHO, 2012, p. 32).

Dessa forma, para incentivar os investimentos internacionais necessários para o crescimento da produção agrícola causando o menor impacto possível seria necessário estabelecer um novo marco legal de gestão fundiária com mecanismos de controle que permitam a redução e a compensação dos impactos sociais e ambientais decorrentes da atividade agropecuária. Esses mecanismos devem ser suficientes ainda, para permitir o crescimento econômico do estado e ao mesmo tempo garantir da soberania nacional uma vez que o capital estrangeiro internacional tem potencial econômico para se apropriar de parte significativa do território estadual, inviabilizando de vez a política agrária. 


\section{OS ASSENTAMENTOS RURAIS}

A principal política pública para a população do rural do estado é a reforma agrária, sendo que seu principal instrumento é a criação de assentamentos rurais. Esta política se deve sobretudo pela existência de uma demanda social para uso da terra, exteriorizada através das manifestaçóes populares organizadas pelos movimentos sociais em resposta a grande concentração fundiária no estado.

Para atendimento desta demanda foram criados diversos mecanismos legais para aquisiçáo de propriedades rurais para fins de reforma agrária. Porém, a criação de um assentamento rural constitui um ato complexo que exige recursos técnicos, humanos e financeiros náo somente para aquisição da propriedade a ser partilhada e distribuída, mais também para promover as condiçóes mínimas para que as famílias contempladas possam morar e produzir no imóvel.

Esse processo de implantação da reforma agrária inicia-se com a aquisição de uma propriedade que será transformada em um assentamento rural sendo condicionada a exigências técnicas como a forma e modalidade escolhida e sua viabilidade econômica apurada por meio do levantamento das potencialidades locais e dos recursos ambientais disponíveis. Depois disso, segue-se a seleção e instalação das famílias que serão beneficiadas, o sorteio do lote que caberá a cada família, a celebração do contrato de concessão de uso, a demarcação da área de reserva legal e proteção ambiental, bem como, a delimitação das áreas de exploração coletiva e de vivência comunitária, que permitirá sua futura urbanização.

Após esta etapa, vem a fase de estruturação do assentamento quando deverá ser implantada a infraestrutura necessária para fixação das famílias (como a abertura de estradas, implantação da rede de água, energia e habitaçóes) e para fomento da produção por meio de financiamento agrícola e contratação de serviço de assistência técnica.

Por último vem a fase de consolidação quando assentamento passa por medidas visando sua titulação com a individualização, certificação e registro das parcelas e urbanização da área coletiva mediante a construção de repartições públicas como escolas, postos de saúde e centro administrativo, além da cessão das áreas reservadas para a instalação de entidades sociais como igrejas, associaçóes, grêmios e clubes recreativos necessárias para permitir uma melhor vivência social e trocas comercias, promovendo a autonomia, independência e emancipação do assentamento.

Devido a sua complexidade o período que decorre da criação de um assentamento rural até sua consolidação e emancipação pode levar muitas décadas, devendo superar uma infinidade de problemas que envolvem desde as dificuldades técnicas na escolha do local, o tamanho dos lotes, os custos e a viabilidade econômica do empreendimento, até questôes de ordem política e econômica, como a escassez de recursos, contingenciamento na liberação das linhas de crédito, manutenção da segurança alimentar, falta de moradia etc., o que explica porque é tâo difícil promover a reforma agrária em grande escala.

Além disso para concretização da reforma agrária é preciso ainda competir por recursos com outras políticas públicas como a previdência, a saúde, a educação e a segurança pública e por recursos naturais e financeiros com a atividade agropecuária, apesar disso, foi possível a criação de 204 Projetos de Assentamentos em Mato Grosso do Sul abrangendo um total de 711.852,19 hectares, o que corresponde a $2,44 \%$ da zona rural do estado. Nestes assentamentos com capacidade para 31.876 famílias, de acordo com o INCRA (2017), vivem aproximadamente 127.504 habitantes ou $36,25 \%$ da população rural do estado, segundo estimativa baseada na quantidade de 4 habitantes por domicílio rural divulgada pelo Censo Demográfico (IBGE, 2010). 
Mesmo com todas as dificuldades enfrentadas na implantaçáo da reforma agrária em Mato Grosso do Sul, um percentual significativo da população rural ainda reside e trabalha nos assentamentos, todavia esta nem sempre foi a realidade do estado, visto que a implantação de projetos de assentamentos teve início somente em meados da década de 1980. Naquela época a população rural ainda representava $1 / 3$ da população total do estado, porém ao longo das décadas este percentual veio sofrendo uma significativa diminuição, sendo reduzida para 14,36\% em 2010 conforme divulgado pelo Censo Demográfico (IBGE, 2010).

Assim, enquanto no início da década de 1980 a população rural de Mato Grosso do Sul correspondia a 33\% da população, nas décadas seguintes houve uma acelerada urbanização, de modo que, apesar do crescimento populacional de $57,25 \%$, houve uma redução de $23,80 \%$ da populaçáo rural do estado. Portanto, essa redução só não foi maior devido a distribuição de terras promovida pela reforma agrária ao longo das quatro décadas seguintes.

Esses dados demonstram a importância dos assentamentos rurais para impedir o êxodo da população rural, freando o aumento da concentração de terras, a redução da pequena produção agrícola e da mão-de-obra no campo, evitando assim, uma crise agrária e os conflitos fundiários, além da precarização dos serviços públicos nas periferias das cidades para onde se destinam as famílias de trabalhadores rurais.

Pela estimativa acima é possível verificar ainda que 5,20\% da população de Mato Grosso do Sul reside em assentamentos rurais da reforma agrária, apesar dos assentamentos ocuparem apenas $1,99 \%$ do território estadual. Dessa forma, a densidade demográfica dos assentamentos rurais de MS (17,07 hab. $\left./ \mathrm{km}^{2}\right)$ é duas vezes e meia maior que a do estado $\left(6,86 \mathrm{hab} . / \mathrm{km}^{2}\right)$ e quatorze vezes maior que a da zona rural $\left(1,20 \mathrm{hab} . / \mathrm{km}^{2}\right)$, demonstrando uma importante concentraçáo demográfica nos assentamentos rurais.

Essa análise da densidade demográfica do meio urbano e rural de Mato Grosso do Sul nos permite verificar o impacto dos assentamentos rurais sobre a composição populacional do estado, constituindo um importante instrumento para o planejamento das políticas públicas para a população do campo, pois segundo Casagrande e Souza (2012) através dos dados obtidos:

[...] torna-se possível diagnosticar as fragilidades e as potencialidades de cada município, realizando assim o planejamento urbano e regional, para que se ofereçam bens, serviços e empregos de acordo com as reais necessidades, proporcionando melhorias a essa população. (CASAGRANDE; SOUZA, 2012, p. 4)

Pelos dados apresentados é possível verificar ainda que os impactos dos assentamentos rurais sobre os municípios são ainda maiores uma vez que a concentração demográfica nos assentamentos é superior a maioria dos municípios do estado, visto que somente Campo Grande (110,71 hab./ $\left.\mathrm{km}^{2}\right)$, Dourados $\left(54,46\right.$ hab./Km$\left.{ }^{2}\right)$, Ponta Porã $\left(17,36\right.$ hab./ $\left.\mathrm{Km}^{2}\right)$ e Naviraí $\left(17,18 \mathrm{hab} . / \mathrm{Km}^{2}\right)$ possuem mais habitantes distribuídos pelo território que os assentamentos rurais. Estes dados permitem demonstrar que os assentamentos também demandam políticas públicas de urbanização de suas áreas comunitárias.

Isto porque, apesar da característica predominantemente rural, os assentamentos da reforma agrariam apresentam uma grande concentração populacional exigindo infraestrutura urbanísticas maiores que grande parte dos municípios do estado. Prova disto é o Assentamento Itamarati que 
possui mais habitantes que a maioria dos municípios, onde seu núcleo urbano apresenta todas as características de uma pequena cidade, embora náo receba o apoio governamental necessário para sua urbanização. Neste sentido o superintendente do INCRA em Mato Grosso do Sul, Celso Cestari (2015) já afirmava que:

Se fosse município, o assentamento Itamarati - localizado em Ponta Porã (MS), fronteira com o Paraguai, com seus 15.867 habitantes, seria o $38^{\circ}$ em população no estado de Mato Grosso do Sul, à frente de cidades como Porto Murtinho, Nioaque e Guia Lopes da Laguna. (INCRA, 2015, p. 1)

Portanto, pelos dados apresentados é possível concluir que a reforma agrária tem impacto não somente com relação a densidade demográfica, visto que em alguns municípios a participação dos assentamentos na composição da população é significativa, chegando em alguns casos a ser maior que a população urbana como no caso dos municípios de Itaquiraí e Novo Horizonte do Sul que possuem mais da metade da população morando em assentamentos rurais. Neste sentido, a $\mathrm{r}$ esidência_dessas pessoas no campo é importante para efetivar reforma agrária, mais também para não provocar um inchaço nas cidades e, consequentemente, transtornos de ordem social, ambiental e econômica nos municípios afetados (TERRA, 2009, p. 209).

Outro fator importante para ser observado quando da análise do processo de implantação de assentamentos rurais é a localização destes no território, isto porque a concentração de assentamentos rurais na mesma localidade produz melhores condiçóes para o êxito do programa, por compartilharem da infraestrutura implantada e permitir uma melhor interação cultural e de trocas comerciais entre as famílias, além intensificar as relaçôes sociais, evitando assim a evasão e o abandono das parcelas.

Foi por isso que procurou-se concentrar os assentamentos rurais em alguns municípios onde estes constituem uma parcela significativa da população, como por exemplo no casos de Ponta Porã que possui 4.506 famílias assentadạs em quinze projetos de assentamentos, Sidrolândia onde 4.399 famílias foram assentadas em vinte e quatro projetos de assentamentos e Itaquiraí com 3.130 famílias assentadas em doze projetos de assentamentos, sendo estes os municípios com maior concentração de famílias assentadas no estado.

Esta concentração de assentamentos rurais num mesmo município tem o objetivo de atender o previsto nos dois planos nacionais de reforma agrária que incentivaram o compartilhamento de infraestrutura e das açóes de todas as políticas sociais, criando uma nova dinâmica na região em que se inserem. Além disso, trazem um grande impacto econômico para o município onde estão inseridos, seja em razão do volume de crédito mobilizado pelas famílias atendidas, que repercute no comércio local e em outras atividades não agrícolas, como em função das demandas por políticas públicas como infraestrutura, saúde, educação, segurança, etc.. Para Heredia et al. (2013):

[...] a existência do assentamento como espaço de referência para políticas públicas, a precariedade da infraestrutura, entre outros fatores, fazem com que os assentamentos tornem-se ponto de partida de novas demandas, propiciando a afirmaçấo de novas identidades e interesses, o surgimento de formas organizativas interiores ao projeto (e também mais amplas) e a busca de lugares onde se façam ouvir. Com isso, os assentamentos acabam trazendo mudanças na cena política 
local, com a presença dos assentados nos espaços públicos e nas disputas eleitorais. (HEREDIA et al., 2013, p. 108)

Dessa forma, entendemos que a localização dos assentamentos rurais é de suma importância para determinar o sucesso dos assentamentos rurais de reforma agrária, visto que dessa interaçáo surgem as condiçóes necessários para reprodução social das famílias atendidas. Além disso, a concentração de assentamentos rurais de determinados municípios constitui um importante instrumento para fortalecimento da economia local, impedindo a evasão das parcelas e o consequentemente o êxodo rural, deixando de gerar novos problemas sociais nas cidades que, via de regra, não estão preparadas para receber esta população.

\section{CONSIDERAÇÕES FINAIS}

Procurou-se ao longo deste artigo demonstrar que o alto índice de concentração fundiária em Mato Grosso do Sul se deve sobretudo a forma de exploração da terra através da produção agropecuária em grandes propriedades rurais. Porém, apesar de incentivar o crescimento econômico do estado esta forma de exploraçáo da propriedade tem causado o desemprego no campo e o êxodo da população rural, estimulando os conflitos agrários e a luta pela terra.

Assim, os principais conflitos agrários no estado se devem a resistência dos trabalhadores rurais expulsos do campo pelo avanço da agricultura sobre as pequenas propriedades e pelo desemprego gerado pela modernização da agricultura que incentivou a organização dos trabalhadores rurais e o surgimento dos movimentos sociais.

Dessa forma os movimentos sociais surgiram em decorrência da organização dos trabalhadores rurais em torno da luta pela terra e, portanto, como uma resposta a concentração fundiária e a expansão da agricultura tendo nas ocupaçóes de terras e no levantamento de acampamentos os principais instrumentos para pressionar o governo para a implantação de reforma agrária.

Por sua vez, a expansão da agricultura culminou no desenvolvimento do agronegócio constituindo o principal entrave para política agrária no estado, na medida em que monopolizou os recursos da política agrícola e a exploração dos recursos naturais, ensejando a diminuição da oferta de terras e o encarecimento do preço dos imóveis rurais, impedindo a aquisição de novas propriedades para criação de assentamentos rurais.

Entretanto, apesar dos entraves criados pelo agronegócio foi possível a criação de 203 projetos de assentamentos rurais de reforma agrária no estado sendo espalhados em todas as regióes visando uma melhor distribuição fundiária. Embora a criação de assentamentos rurais não tenha sido suficiente para alterar a estrutura fundiária do estado tem contribuído para a democratização do acesso à terra, impactando positivamente sobretudo naqueles municípios com a maior concentração de famílias assentadas.

\section{REFERÊNCIAS}

ALMEIDA, Rosemeire Aparecida de. Identidade, Distinção e Territorialização: o processo de (re) criaçáo camponesa no Mato Grosso do Sul. Presidente Prudente: Unesp, 2003. 
BORGES, Maria Celma; KUDLAVICZ, Mieceslau. História e Vida da CPT em Mato Grosso do Sul: contribuição na luta pela terra e para nela permanecer. In: ALMEIDA, Rosemeire (Org.). A Questáo Agrária em Mato Grosso do Sul: uma visáo disciplinar. Campo Grande: Editora UFMS, 2008.

BUSCIOLI, Roberson da Rocha. Estratégias de Crescimento Polarizado e sua Relação com a (Re)Produção do Espaço Sul-Mato-Grossense: uma análise da tendência à concentração.

Revista Entre-Lugar: Dourados/MS. Ano 1, no 2, pp. 119-144, 2010. Disponível em http://ojs.ufgd.edu.br/index.php/entre-lugar/article/view/653. Acesso em 20/01/2020 às 14:30.

CASAGRANDE, Adriana Eliane; SOUZA, Edson Belo Clemente de. O Espaço e a Demografia: o planejamento regional em perspectiva nas margens paranaenses do Lago de Itaipu. Revista Sociedade e Território. Natal/RN: v. 24, n. 1, p. 2-27, 2012. Disponível em https://periodicos.ufrn.br/sociedadeeterritorio/article/ view/3461. Acesso em 20/01/2020 às 15:00.

CASTILHO, Marcelo Ambrogi. Determinantes do Preço da Terra no Mato Grosso do Sul. Trabalho de Conclusão de Curso (Graduação em Ciências Econômicas) Campinas: Unicamp, 2012. Disponível em file:///C:/Users/Home/Downloads/CastilhoMarceloAmbrogi TCC\%20(2).pdf. Acesso em 20/01/2020 às 15:30.

COELHO, Fabiano. A Prática da Mística e a Luta pela Terra no MST. Dissertação (Mestrado em História) Dourados: UFGD, 2010.

CORTEZ, C. A Travessia do Rio dos Pássaros. Belo Horizonte: SEGRAC, 1985.

FABRINI, João Edmilson. A Posse e Concentração de Terras no Sul de Mato Grosso do Sul. In: ALMEIDA, Rosemeire (Org.). A Questáo Agrária em Mato Grosso do Sul: uma visáo multidisciplinar. Campo Grande: Ed. UFMS, 2008.

FALCHI, Edna. Na Luta por um Pedaço de Chão: experiência e Cotidiano nos acampamentos de sem-terra do sul de Mato Grosso do Sul. Dissertação (Mestrado em História) Dourados: UFGD, 2007.

FREITAS, André Alexandre Ricco de; NUNES, Fábio de Almeida. Os Brasiguaios e a Reforma Agrária na Região de Fronteira em Mato Grosso do Sul. Anais do VI Seminário Leituras de Fronteiras, Asunción/PY: UFGD/UNA. v. II, nº 1, pp. 357-364, 2018.

HEREDIA, Beatriz; MEDEIROS, Leonilde; PALMEIRA, Moacir; CINTRÃO, Rosangela e LEITE, Sérgio Pereira. Análise dos Impactos Regionais da Reforma Agrária no Brasil. Estudos Sociedade e Agricultura, v. 1, p. 73-111, 2013. Disponível em https://revistaesa.com/ojs/index.php/esa/article/view/209. Acesso em 20/01/2020 às 16:00.

IBGE, Instituto Brasileiro de Geografia e Estatística. Censo Demográfico 2010: Área territorial brasileira. Rio de Janeiro: IBGE, 2011. Disponível em: https://www.ibge.gov.br/cidades-e-estados/ms/.html?. Acesso em 20/01/2020 às 11:00.

. Estatísticas de imóveis rurais. Estrutura Fundiária de Mato Grosso do Sul. Disponível em: http:// www.incra.gov.br/estrutura-fundiaria/estatisticas-de-imoveis-rurais. Acesso em 20/01/2020 às 12:00. 
Núcleo urbano do Assentamento Itamarati é transformado em distrito de Ponta Porã/MS. Caderno de Notícias. publicado em 13/03/2015. Disponível em http:// www.incra.gov.br/noticias/nucleo-urbano-do-assentamento-itamarati-e-transformado-em-distrito-de-ponta-porams. Acesso em 20/01/2020 às 13:30 horas.

. Painel de Assentamentos. Disponível em Acesso em 20/01/2020 as 18:00. http://www.incra.gov. $\underline{\mathrm{br} / \mathrm{ms}}$.

MELO, Danilo Souza. A luta pela terra em Mato Grosso do Sul: o MST e o protagonismo da luta na atualidade. Revista Nera. Presidente Prudente: Unesp, Ano 20, no 39, p. 133-160, 2017. Disponível em: $\underline{\text { h }}$ ttp://revista.fct.unesp.br/index.php/nera/article/view/4204. Acesso em 20/01/2020 às 14:00.

MENEGAT, Alzira Salete. No Coraçáo do Pantanal: assentados na lama e na areia, as contradiçóes entre os projetos do estado e dos assentados no assentamento Taquaral -MS. Dourados: E d i t o r a UFGD, 2009. Disponível em http://biblioteca.clacso.edu.ar/Brasil/fch-ufgd/20170919030820/ pdf 95.pdf. Acesso em 20/01/2020 as 16:30.

NERA. Núcleo de Estudos, Pesquisas e Projetos de Reforma Agrária. DATALUTA. Banco de Dados da Luta Pela Terra: Relatório Brasil 2016. Presidente Prudente: Unesp, 2017. http://www2.fct.unesp.br/ nera/projetos/dataluta brasil 2016.pdf. Acesso em 20/01/2020 às 11:30.

OLIVEIRA, Ariovaldo Umbelino de. A Mundialização da Agricultura Brasileira. São Paulo: Iandá Editorial, 2016. Disponível em http://www.ub.edu/geocrit/coloquio2012/actas/14-A-Oliveira.pdf. Acesso em 20/01/2020 as 17:00.

PRADO JÚNIOR, Caio. A Questáo Agrária no Brasil. São Paulo: Editora Brasiliense, 1979.

SEMADE. Secretaria de Meio Ambiente e Desenvolvimento Econômico, Produção e Agricultura Familiar. Perfil Estatístico de Mato Grosso do Sul 2016. Campo Grande: BDE, 2016. Disponível em: http://www. seinfra.ms.gov.br/wpcontent/uploads/2017/06/Perfil_Estat\%C3\%ADstico_MS_20 pdf. Acesso em 20/01/2020 às 13:00.

SILVA, Tânia Paula da. As formas Organizacionais de Produçáo dos Camponeses Assentados no Município de Batayporã/MS. Dissertação (Mestrado em Geografia) Presidente Prudente: Unesp, 2004.

TERRA, Ademir. Reforma Agrária por Conveniência e/ou por pressão? Assentamento Itamarati em Ponta Porã- MS: “o pivô da questáo”. Tese (Doutorado em Geografia) Presidente Prudente: Unesp, 2009.

VANESKI FILHO, Ener. Os Brasiguaios Sem-Terra na Reforma Agrária. Revista Nera. Presidente Prudente: Unesp. Ano 19, no 34, pp.119-143, 2016. Disponível em http://revista.fct.unesp.br/index.php/nera/article/viewFile/4981/4138. Acesso em 20/01/2020 as 17:30. 